\title{
The Differential Influence of Learner Factors and Learning Context on Different Professional Learning Activities
}

\author{
Frederic Hilkenmeier $^{1}$ (D) $\cdot$ Michael Goller $^{2} \cdot$ Niclas Schaper $^{3}$
}

Received: 27 May 2019 / Accepted: 10 February 2021 / Published online: 12 April 2021

(C) The Author(s) 2021

\begin{abstract}
Participation in designated learning opportunities and engagement in workplace learning are very different kinds of professional learning activities: Whereas the former takes place in organised, predefined settings with intended learning objectives, the latter mostly arises as a by-product through everyday experiences at work. Yet, empirical and theoretical models often do not sufficiently differentiate between these two kinds of learning activities. The main goal in the present study is to test whether the two discrete learning activities are indeed facilitated in different ways and by different antecedents. The results of a multi-wave diary study with a sample of 229 German employees show that engagement in workplace learning is not influenced by conscious beliefs connected to learning, which play a central role in most theoretical models explaining participation in designated learning opportunities, underlining the need for an autonomous theory of workplace learning. Furthermore, the current study shows the strong direct, indirect, and moderating influence of organisational learning culture on both kinds of professional learning activities. Possible implications for practitioners to put greater emphasis on organisational factors when designing learning opportunities are discussed.
\end{abstract}

Keywords Workplace learning · Formal learning · Informal learning · Learning culture · Partial Least Square Structural Equation Modelling (PLS-SEM)

Frederic Hilkenmeier

frederic.hilkenmeier@gmail.com

Michael Goller

michael.goller@upb.de

Niclas Schaper

niclas.schaper@upb.de

Extended author information available on the last page of the article 


\section{Introduction}

Over the last two decades researchers have devoted considerable attention towards investigating what individual and situational characteristics might influence employees' involvement in learning activities within formal education contexts and how to develop training programs that make it more likely that the learned knowledge is actually transferred into daily work (e.g., Blume et al. 2010; Gegenfurtner et al. 2009; Govaerts et al. 2017). This line of research has considerably increased the understanding about the effectiveness of such instructor-focused training activities as well as generating a range of practical implications on what effective training should look like.

Apart from research investigating this institutionalised training, there is also an increasing body of literature focusing on employees' learning that takes place outside formal education programs through participation in daily work practices. Such workplace learning plays a crucial role in constructing professional knowledge and building up expertise in the context of work (e.g., Billett 2014; Gruber and Harteis 2018; Kyndt et al. 2009; Nieuwenhuis and van Woerkom 2007). Workplace learning is largely a by-product of everyday tasks and problem solving as well as social interaction at work (Billett 2004). Thus, it is rarely regarded as a learning activity by the learners themselves (Eraut 2004), making it and its antecedents difficult to assess in larger quantitative survey studies (see also Simons and Ruijters 2001). Although a range of scholars have committed themselves to this issue in recent years, we still have-in comparison to learning within formal education contextscomparatively little empirical grounded knowledge about personal, motivational, and situational factors that affect engagement in workplace learning, since only a fraction of published empirical hypothesis-testing studies have considered workplace learning as a dependent variable (see Cerasoli et al. 2017, citing over a dozen meta-analyses for more formal work-related learning, but only one focusing on workplace learning as such; also see Kyndt and Baert 2013).

Moreover, research on the antecedents of various kinds of learning activities remains largely unrelated. In fact, almost no studies have investigated how different individual and situational factors affect both employees' participation in more formal educational programs as well as engagement in learning within the context of their workplaces using identical samples (see Maurer et al. 2003, for an exception). It is, however, such study designs that allow strong differential propositions to be made about predictors of professional learning activities that theoretically differ in nature. Within our own study we want to follow this route to bridge the described research gap. To be more concrete, a multi-wave study with a usable sample of 229 employees was conducted to investigate whether participation in learning activities within formal education programs as well as engagement in learning that takes place in work contexts is affected by different theoretically derived antecedents. Thereby, our study answers Cerasoli et al.'s (2017) call to further advance science and practice by empirically testing the antecedents of different kinds of learning activities. However, before presenting and discussing both the method and the findings of this study, the next sections will first define and conceptualise our perspective on two distinct professional learning activities and will derive hypotheses about potential antecedents of these learning activities based on theoretical assumptions and prior research findings. 


\section{Setting the Stage: About the Different Nature of Professional Learning Activities}

Professional learning describes the process by which employees develop and thereby expand their personal capacities to deal effectively and efficiently with the full range of requirements of their current and future workplace. Within the literature, traditionally, two different kinds of learning activities are distinguished: (a) participation in designated learning opportunities that take place outside ongoing working practices, and (b) engagement in learning affordances directly at work within the context of ongoing working practices. These different kinds of learning activities are often also referred to as formal and informal learning (e.g., Eraut 2000; Marsick and Watkins 2015). However, due to conceptual difficulties connected to this duality, discussed elsewhere, it was decided not to use this particular terminology here (see Billett 2004; Doornbos et al. 2004; as well as Tynjälä 2008, for a discussion on this issue).

The first kind of learning activity will be labelled participation in designated learning opportunities. There are two core characteristics of designated learning opportunities. First, they are explicitly planned for knowledge as well as skill development, be it by supervisors, external educational providers, or the employee her/ himself. Second, they do not aim to tackle ongoing and pressing work-related tasks or problems. Instead, the goal of participation in designated learning opportunities is to acquire a deeper understanding of work-related issues that might help responding to new challenges beyond the immediate demands of the workplace (see e.g., Butler and Brooker 1998; Vaughan 2008). Typical examples are attending workshops, seminars, or conferences. However, designated learning opportunities also subsume pre-planned instruction at the workplace, structured job rotation, or a regular inter-collegial consultation group (see e.g., Vaughan 2008). The defining characteristic is that these activities take place in a designated and somehow a priori structured context that aims at learning and developing using pedagogic means. Of course, participation in these designated learning opportunities does not necessary lead "to the unquestioned learning of what is afforded [...]. Individuals are active agents in what and how they learn from these encounters" (Billett 2001, p. 211), and it is entirely possible that participants only master the learning content in a superficial way (e.g., Wertsch 1998), or learn something not intended by the designated curriculum (e.g., Decker and Martino 2013; or Park et al. 2016 for a different domain). However, in terms of Butler and Brooker (1998), the priority of designated learning opportunities is indeed learning, meaning that the expectation (and intention) when participating in designated learning opportunities like workshops or seminars is to learn something new.

The second kind of learning activity will be described as engagement in workplace learning, or -in short- workplace learning. In our understanding learning activities of this kind are driven by employees' needs to tackle unfolding and pressing tasks or problems at work. They do not aim at knowledge and skill development that could help employees in a more or less distant future. Instead, these activities aim at coming up with suitable strategies to tackle the situation currently at hand. Typical examples are experimenting with new work strategies, discussions with colleagues, participating in team meetings, as well as task-related reading of codified information like manuals or books that help to meet any current challenges at work. Workplace learning takes place directly in the context of work and is concerned with, in terms of Butler and Brooker 
(1998), "production"- that is, task and problem solving but not learning and development. Knowledge and skill acquisition, nevertheless, is a highly relevant side effect of such direct engagement in real work practices. However, the acquired knowledge and skills are most likely highly contextualised (i.e., specific to the current workplace) and might therefore be especially useful in a "business as usual" scenario but reach their limits in more radical transformation processes (Vaughan 2008).

\section{Explaining Employees' Engagement in Professional Learning Activities}

Many theories regarding individuals' participation in designated learning opportunities directly or indirectly draw on Ajzen's (1991) theory of planned behaviour - that is, the learning behaviour in question is assumed to be intentional and consciously planned. Whether or not an individual intends to participate in the learning activity depends on her or his attitudes and beliefs towards learning, which in turn are influenced by some more distal variables like work involvement, abilities, and situational factors (e.g., Maurer et al. 2003; Hurtz and Williams 2009). Indeed, we would agree that this sequence of relationships is well suited for learning endeavours with designated trainers, schedules, agendas, and learning outcomes. Whether employees participate in such developmental activities is usually highly intentional and planned (e.g., Kyndt and Baert 2013). For instance, employees in a number of countries can take several days of paid educational leave each year (ILO 1974). To do so, they must determine their learning needs, find a suitable training program with the help of their supervisors or HRD personnel, enrol in the training course, and find someone to fill in for them at work. One can easily argue that it is more likely for employees to show this highly planned behaviour if they have positive beliefs in regard to learning - that is, if they have a high self-efficacy for their own learning, expect benefits from the learning activity, and thus feel favourably towards learning. Indeed, Pierce and Maurer (2009) were able to show that participation in developmental activities increases if employees expect benefits from the learning activity. Furthermore, Maurer et al. (2003) evidenced that attitudes towards learning have a substantial effect on employees' participation in designated learning. Moreover, Maurer and Tarulli's (1994) results indicate that "potential participants need to believe that they will actually succeed at learning tasks if they commit themselves to participation" (p. 5), underlining the strong influence of self-efficacy. This also holds for learning activities partially or fully organised by an employee's employer. After all, employees also have to attune themselves to the upcoming learning challenges in such cases. So again, positive beliefs in regard to learning should be beneficial for learning and development.

By contrast, there exists no comparable comprehensive theory or "meta" theory that systematically categorises potential antecedents explicitly for engagement in workplace learning (Cerasoli et al. 2017). This might be the reason why some studies implicitly assume that both kinds of learning activities are influenced by the same antecedents in the same way. The seminal work of Maurer et al. (2003), which tested a complex mediated model of different individual, situational, as well as motivational variables to explain participation in a mixture of designated as well as non-designated developmental activities, is indicative for most of the models in this line of research. 
However, as discussed in the previous section, workplace learning arises through everyday participation in work practices (i.e., engagement in activities and interactions) and is related to the employees' current situation and, thus, is more spontaneous (Billett 2004; Eraut 2000). This means that the workplace learning process itself - that is, its objectives, content, and means of acquisition - is not intentionally pre-planned. Therefore, we would argue that individual beliefs in regard to learning, like attitudes or selfefficacy, are less relevant in predicting workplace learning than they are in predicting employees' participation in designated learning opportunities. In other words, if it is not the employee's explicit goal to learn, her or his perceived benefits of learning, her learning-related attitudes, or her self-efficacy in regard to learning should not be the most relevant predictors.

Instead, more work-related attitudes such as job involvement, career-planning tendencies, and vocational identity - that is, how employees identify themselves with their work, how important this work is in their lives, and how cognitively involved they are with their work (Gould 1979)—should predict to what extent employees actively engage in nonroutine situations that offer opportunities for workplace learning (e.g., Tynjälä 2013). These concepts have been seen as central to employees' agency and commitment and have been linked to participation in learning activities (e.g., Goller and Paloniemi 2017; Maurer and Tarulli 1994; Noe and Schmitt 1986). For instance, Richter et al. (2011) found a correlation between work engagement and workplace learning activities. Moreover, Rowold and Shilling (2006) reported that job involvement predicted subsequent continuous work-related learning. This means that the more employees see their work as central to their lives, the more they identify with their work and want to engage with it. For instance, they will actively try to tackle new and challenging work tasks, deliberately reflect on their own work, or discretely discuss it with colleagues (Goller 2017; Goller and Billett 2014). During these activities, they will encounter and seize various opportunities to learn; however, this learning is only a by-product of trying to improve their job performance (Goller 2017). Of course, these work-related attitudes are also known to have an impact on participation in designated learning opportunities and learning transfer (e.g., Maurer et al. 2003). However, research suggests that this influence on participation in designated learning opportunities is largely mediated by motivational and attitudinal variables. For instance, Maurer et al. (2003) found an indirect link from work-related career variables to beliefs and attitudinal variables and then to participation. In contrast, we argue that the influence of work-related attitudes on workplace learning is direct, without the detour by such motivational factors (see e.g., Berg and Chyung 2008, or Lohmann 2006, who found interest in the profession [as a work-related attitude] is a major driver for engagement in workplace learning; also see, e.g., He and Zhu 2017, who found that the direct effects of content-related attitudes on participation in digital informal learning activities were much stronger than the indirect effect mediated by attitudes towards learning).

Besides these antecedents regarding the individual learner (i.e., work-related attitudes and learning-related beliefs), the organisational learning context is at least equally influential on the way employees learn (e.g., Kyndt et al. 2018). By successfully implementing policies, structures, and processes, organisations potentially enable a culture that is conducive to learning and knowledge sharing (e.g., Fischer and O'Connor 2014; Gruber and Harteis 2018). As research indicates, several facets of organisational learning culture have been stressed as important learning affordances. 
For instance, many authors have emphasised the role of interpersonal support, especially of supervisors in both creating a stimulating work environment and encouraging subordinates to participate in learning activities (e.g., Baron 2011). As Cerasoli et al. (2017) suggest, supervisors can encourage employees to engage in more deliberate learning activities as well as providing them with appropriate decisional discretion, allowing them to solve new and unexpected problems on their own. Likewise, other research has found that coworker support - that is, a "psychological safe" climate in which coworkers help each other out, solve problems together, and give constructive feedback — creates room for applying learned skills to the job (e.g., Facteau et al. 1995). Besides interpersonal support through coworkers and supervisors, more institutionalised support also impacts participation in professional learning activities: This institutionalised support can entail efforts to manage knowledge within the organisation, as well as facilitatory human resource management practices in general that provide development opportunities (e.g., Cerasoli et al. 2017). Empowermentthat is, the extent to which employees experience the freedom to tackle their challenges on their own - is also viewed as a significant facet of learning culture. As Li and Liu (2014) note, "the more employees are encouraged to have the desire and ability to manage themselves [...], the easier it is to promote the establishment of an organizational learning culture" (p. 55). This entails self-organising and advancing their knowledge as well as establishing networks with members of other organisations with different skills and knowledge bases. Indeed, Janz and Prasarnphanich (2003) found a strong link between empowerment and learning activities (for related results, see Gijbels et al. 2012).

To understand the interplay of organisational learning context and individual learner factors on participation in designated learning opportunities as well as engagement in workplace learning, these variables cannot be investigated in an isolated manner, but must be analysed simultaneously (Kyndt and Baert 2013). In underlining the interdependence of individual and organisational factors, Billett (2001) has coined the term "co-participation" - that is, how "workplaces afford opportunities for learning and how individuals elect to engage in activities and with the support and guidance provided by the workplace" (p. 209). However, existing research on learning has the tendency to empirically overemphasise either personal or situational variables, ignoring the relationship between the individual learner factors and the learning context (e.g., Berg and Chyung 2008; Billett 2004), despite empirical evidence supporting a strong moderating role of the latter (e.g., Pierce and Maurer 2009).

\section{Using the 3-P Model of Learning to Derive Hypotheses}

Tynjälä (2013) introduced the "3-P model” of learning that combines all the variables discussed above into a comprehensive theoretical framework of work-related learning (see also Gruber and Harteis 2018, for a recent adaptation and integration of the model into the expertise literature). It is based on the original 3-P model by Biggs (1999) and refers to the three interrelated components of learning phenomena in general: presage, process, and product, which are adapted for the workplace context.

As can be seen in Fig. 1, the presage component contains both individual learner factors concerning work-related attitudes like agency and commitment, and individual 


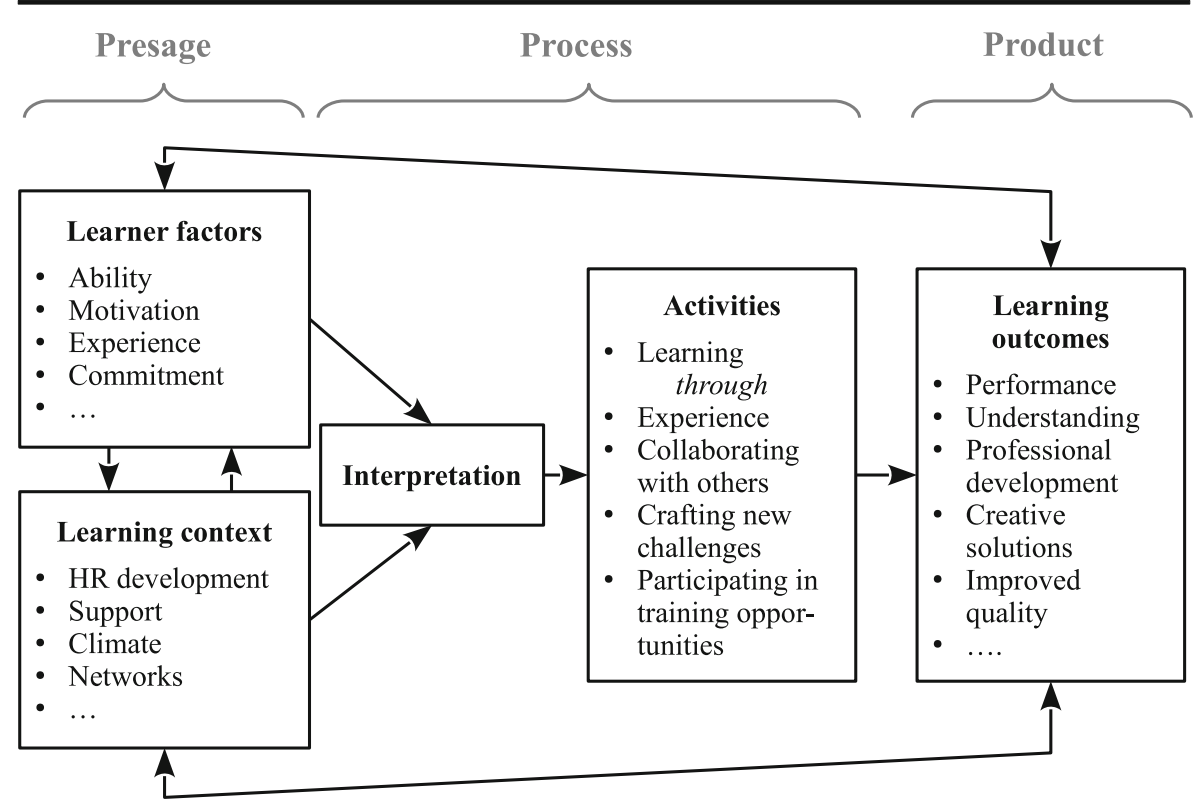

Fig. 1 The 3-P model of learning (slightly adapted from Tynjälä 2013)

learner factors concerning beliefs in regard to learning like motivation, or self-confidence, as well as situational variables concerning the learning context like human resource development, manager support, or collaborative climate. Importantly, whether or not these variables lead to the participation or engagement in learning (the process component) depends on the personal interpretation of the presage factors - that is, the presage factors do not affect the learning process directly, but rather through the learner's interpretation of these factors (Tynjälä 2013). The process component describes different kinds of learning, like participation in designated learning opportunities or engagement in workplace learning activities through which learning processes take place. Finally, the product component comprises various learning outcomes like task performance, increased productivity, improved product quality, or personal development. Within the model, these outcomes depend both directly on the presage factors as well as on the learning activities detailed in the process component.

Tynjälä (2013) presents her 3-P model as a tentative holistic model that aims at structuring a wide and diverse research field and offers an outline for research designs in future studies. In this spirit, we use her model as a research framework to investigate differential influences of learner and learning context factors on participation in designated learning opportunities and engagement in workplace learning activities, thus concentrating on the presage component as independent and the process component as dependent variables. Based on the theoretical arguments made above, three interdependent, higher-order factors representing the presage component are included in our research model: work-related attitudes, learning-related beliefs, and perceived organisational learning culture. The work-related attitudes represent how employees identify themselves with their work, how central work is for them, and whether they are inclined to engage proactively with their career development. The learning-related beliefs can be defined as employees' attitudes and beliefs about professional learning 
and development that affect how they engage in and regulate learning activities. And last, the perceived organisational learning culture describes the organisational context in terms of its conduciveness to professional learning and development (e.g., through certain affordances like coworker and supervisor support or opportunities for boundary crossing; see also Fuller and Unwin 2004). As will be seen in the methodological description of this study, all three factors are operationalised by more concrete first-order constructs (e.g., job involvement for the work-related attitudes; self-efficacy beliefs concerning learning for learning-related beliefs; coworker support for the perceived organisational learning culture). From a theoretical point of view, the decision in favour of more abstract factors relating to each other in our model is grounded in the fact that the underlying framework of the 3-P model is also based on higher-order constructs. Furthermore, we are less interested in how specific attitudes, beliefs, or cultural facets explain learning. Instead, it is assumed here that more general factors-introduced here as work-related attitudes, learning-related beliefs, and perceived organisational learning culture-have exploratory power to predict incumbents' engagement and participation in learning activities. In addition, such a theoretical specification helps to construct a rather parsimonious model that can be tested even with relatively small samples.

In detail, we hypothesise that deliberately planned participation in designated learning opportunities is strongly and directly influenced by conscious learning-related beliefs, as predicted by the "meta" theory of planned behaviour. Influences of more distal variables - that is, variables that are not directly related to learning, like work-related attitudes - should be mediated by these proximal learning-related beliefs. In contrast, these learning-related beliefs should be less relevant for engagement in workplace learning, in which knowledge and skill acquisition are only side effects of tackling a pressing work-task. Instead, engagement in workplace learning is hypothesised to be directly predicted by work-related attitudes. Individuals who experience their jobs as highly important and relevant for their lives should be willing and inclined to engage more often in nonroutine situations that offer opportunities for workplace learning (Goller 2017).

Moreover, since workplace learning is learning through work, a learning supportive culture within the organisation should be at least equally influential on the way employees learn (Clardy 2000). In contrast, the influence of such a supportive culture on participation in designated learning opportunities which take place within formally designated learning contexts and therefore often outside the regular structures of work, should be attenuated. In the following, we will formalise our research hypotheses, the overall hypothesised model can be seen in Fig. 2.

Hypothesis 1 deals with the interrelations within the presage component: In line with the "meta" theory of planned behaviour, we would expect that the more distal work-related attitudes and the perceived organisational learning culture will influence learning-related beliefs. This is in line with Noe (1986) or Maurer et al. (2003) who hypothesised and established links between elements of work-related attitudes and learning-related beliefs. Likewise, Mathieu et al. (1992), Maurer et al. (2003), and LePine et al. (2004) could show links between elements of organisational culture and learning-related beliefs. 


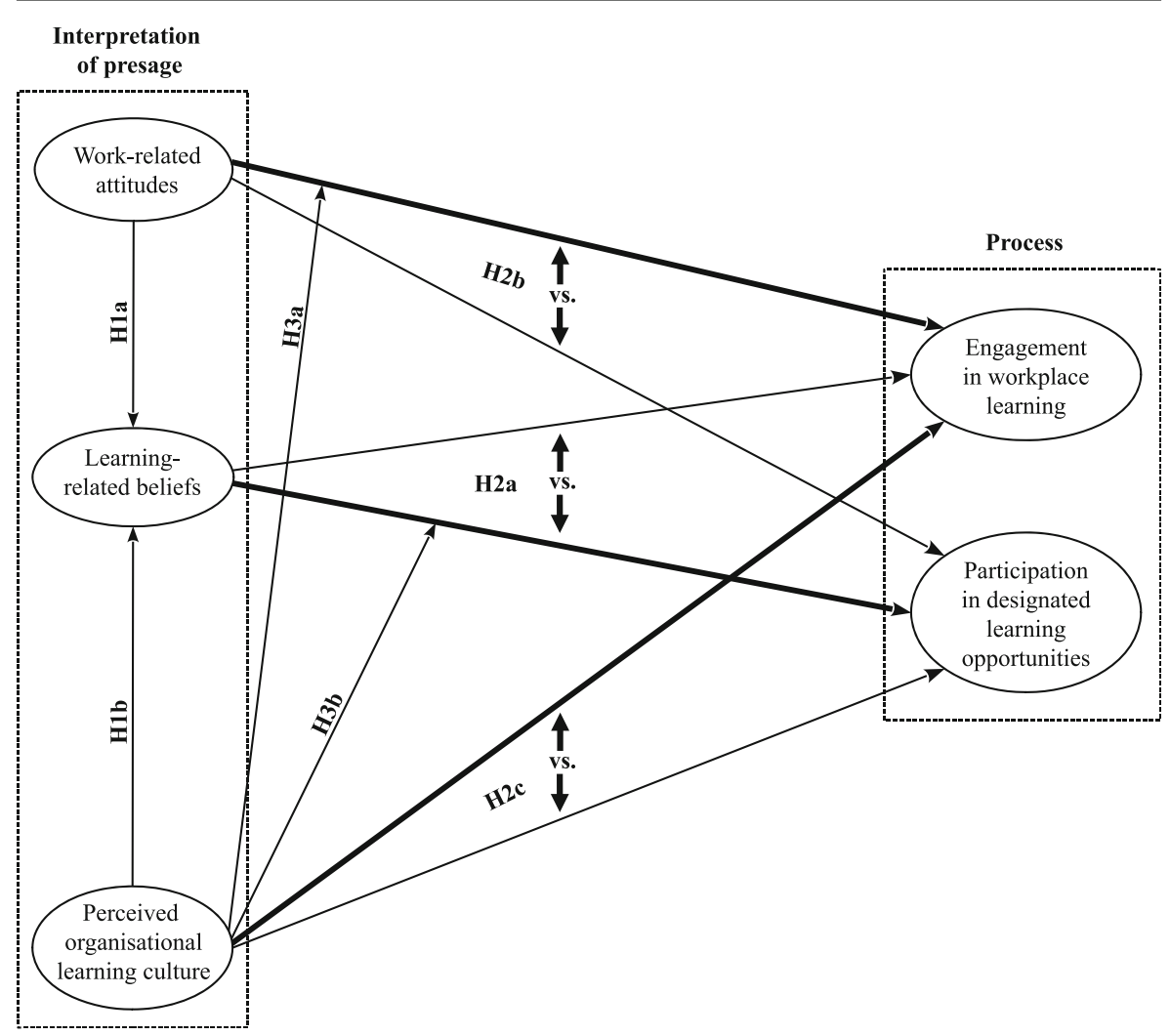

Fig. 2 Hypothesised theoretical model. Note. Thickness of lines between presage and process factors represents relative strength of relationship. All relationships are assumed to be positive

H1a: Work-related attitudes will be positively related to learning-related beliefs. $H 1 b$ : Perceived organisational learning culture will be positively related to the learning-related beliefs.

Hypothesis 2 deals with the differential influences of the factors within the presage component on participation in designated learning opportunities and workplace learning. As discussed, we would anticipate that learning-related beliefs will positively predict participation in designated learning opportunities, since these activities are consciously planned and intentionally started. However, learning-related beliefs should have little to no influence on engagement in workplace learning, in which knowledge and skill acquisition are only side effects of tackling a pressing work-task. Instead, employees with positive work-related attitudes should more strongly engage with their work and thus find themselves in situations that offer opportunities for workplace learning more often (e.g., Richter et al. 2011; Rowold and Shilling 2006). Given that hypothesis H1a holds true, the influence of these work-related attitudes on participation in designated learning opportunitites should (largely) be mediated by learningrelated beliefs. As evidenced by Berg and Chyung (2008), or Janz and Prasarnphanich (2003), for example, organisational learning culture is positively related to workplace learning. In fact, the meta-analysis of Cerasoli et al. (2017) indicates that the 
organisational context has a larger influence than individual learning factors. In contrast, results from van der Heijden et al. (2009) or Facteau et al. (1995), for example, show non-significant or relatively small correlations between elements of an organisational learning culture and participation in designated learning opportunities, suggesting an attenuated effect.

H2a: Learning-related beliefs will be more strongly related to participation in designated learning opportunities than to engagement in workplace learning. $H 2 b$ : Work-related attitudes will be more strongly related to engagement in workplace learning than to participation in designated learning opportunities.

H2c: Perceived organisational learning culture will be more strongly related to engagement in workplace learning than to participation in designated learning opportunities.

Hypothesis 3 deals with the concept of co-participation (Billett 2001), which stresses the interplay between organisational and individual factors: Employees can only engage in learning activities if the workplace affords any opportunities for learning in the sense of a work climate that is conducive to learning, or if the workplace has an active human resource department that offers developmental programs. Therefore, the organisational learning culture should moderate the relationship between the learner factors and the engagement or participation in learning activities, be it designated or less designated ones. This moderating role of organisational culture has been found previously (e.g., Pierce and Maurer 2009). However, further studies investigating the influence of contextual moderators, especially on workplace learning, are needed (Cerasoli et al. 2017).

H3a: Perceived organisational learning culture will moderate the relationship between the work-related attitudes and engagement in workplace learning.

$H 3 b$ : Perceived organisational learning culture will moderate the relationship between the learning-related beliefs and participation in designated learning opportunities.

To our knowledge, this is the first time that all these factors have been investigated at once with the focus on differentiating between influences on different professional learning activities. This endeavour is even more justified since the comparatively few quantitative studies that have focused on workplace learning activities often came to results contradicting those of studies focusing on designated or mixed learning activities when investigating the very same variables (e.g., age, gender, or education level; Berg and Chyung 2008; Ito and Brotheridge 2005; Schulz and Stamov-Roßnagel 2010). As outlined, we have good reason to believe that, due to the different nature of professional development activities, learner factors and learning context should have differentiated influences on participation in designated learning opportunities and engagement in workplace learning. It follows that this study contributes to the understanding about the differential effects of a range of theoretically derived individual and organisational presage and process factors on individuals' participation in designated learning opportunities and engagement in workplace learning, respectively. 


\section{Method}

\section{Research Design}

The study was conducted to test the seven theoretically derived hypotheses employing a (partial) longitudinal research design based on a 9-week study (pre-test questionnaire measuring both the independent variables as well as participation in designated learning opportunities and subsequent diary questionnaires for 8 weeks measuring engagement in workplace learning). The self-reported data were collected using questionnaires containing mostly items with a closed answer format. Following the suggestions of Maurer et al. (2003), data collection was entirely independent of participants' employers to minimise social desirability and, at least for workplace learning activities, it separated the data collection of independent and dependent variables in time to further increase the quality of our data. Participants received a voucher worth $20 €$ for a big online retailer after completion of all study requirements as well as a raffle ticket for a voucher worth $150 €$ for the same online retailer. All participants were invited to fill in their data via mail.

\section{Participants}

This study is based on a convenience sample of 263 German employees in total. Participants were recruited using social networks. Unfortunately, 34 study participants did not answer a substantial share of the administered questionnaire and their data could therefore not be used for any analyses. This reduced the usable sample size to 229 (49\% female). These final participants worked in different industry sectors all over Germany: $35 \%$ were employed in the secondary sector (industrial production), whereas $65 \%$ worked in the tertiary sector (public and private service, banking and commerce, public health, etc.). Forty-four percent of our participants worked in companies with fewer than 250 employees, $33 \%$ worked in companies with between 250 and 500 employees, and $23 \%$ worked in companies with more than 500 employees. Of our sample, $33 \%$ was between 36 and 45 years old, followed by $30 \%$ aged between 46 and 60 years; $32 \%$ of the overall sample was younger than 35 years, and only $5 \%$ were older than 60 years. Regarding formal education, $9 \%$ in our sample reported a lower certificate of secondary education, $35 \%$ a higher certificate of secondary education, and $56 \%$ a university entry qualification. Although this sample is not representative for employees in Germany, the overall gender and age structure fit the underlying population relatively well with an overrepresentation of employees between 36 and 45, and an underrepresentation of employees over 45 (German Federal Statistical Office 2018, 2019). Moreover, in our sample, we have a slight overrepresentation of the secondary sector compared to the tertiary one, as well as a strong overrepresentation of higher formal education.

\section{Measurement Points and Survey Administration}

As foreshadowed, a longitudinal study design based on one larger questionnaire $\left(\mathrm{t}_{0}\right)$ and eight consecutive smaller diary questionnaires was employed ( $\mathrm{t}_{1}$ to $\left.\mathrm{t}_{8}\right)$. All presage factors (work-related attitudes, learning-related beliefs, and perceived organisational 
learning culture) including the dependent process factor participation in designated learning opportunities were measured within $\mathrm{t}_{0}$ one week before the participants were asked about their workplace learning experiences. The dependent process factor workplace learning was then collected using a diary-like study in which participants had to fill out an identical short questionnaire about their last week's learning experience once a week over a time span of 8 weeks, $t_{1}$ to $t_{8}$ (see for discussions on the diary method: Rausch 2013, 2014). By default, data collection lasted 9 consecutive weeks; however, in case participants were on vacation or otherwise absent in a given week, they were asked not to fill out that week's questionnaire but to make up for it afterwards.

This differential data collection of participation in designated learning opportunities and engagement in workplace learning is well suited to the different nature of the two kinds of professional development activities. For participation in designated learning opportunities, the period under consideration of one year should allow for a stable sample of the individuals' designated developmental activities (e.g., Maurer et al. 2003; Pierce and Maurer 2009). In contrast, several scholars have emphasised that employees have problems recalling engagement in workplace learning when asked about such endeavours (e.g., Eraut 2004; Simons and Ruijters 2001). Therefore, workplace learning was assessed in a much shorter time frame by asking employees to fill out a short diary about their learning experiences during the previous week. Since workplace learning activities of a randomly chosen week are not necessarily indicative of an employee's usual learning behaviour, we decided to collect these data repeatedly over a time span of 8 weeks to increase reliability and reach a stable sample of the individuals' learning behaviour. The multiple measures not only were thought to increase the reliability of the data but should also make participants more aware of their learning at work. By the third week at the latest, participants should have anticipated the questions and should therefore be monitoring their own learning experiences of the given week to fill in the diary appropriately. In short: Even though we acknowledge that the two dependent factors participation in designated learning opportunities and engagement in workplace learning are measured in different ways, we argue that the respective measure is suited to the specific nature of the context of learning in question and that therefore, in effect, the two dependent factors are highly comparable.

\section{Measures}

General Notes on Construct Operationalisation As it is clear from Figs. 1 and 2, the components of the 3-P model are constructs with a relatively high level of abstraction that incorporate several discrete facets each. To reproduce this structure properly in our model and in line with Law et al. (1998), we decided to operationalise our independent constructs as formative second-order ones with several facets (i.e., reflective first-order constructs) each. This measurement structure is what Diamantopoulos et al. (2008) classify as a Type II measurement model and allows us to integrate different first-order constructs which each have unique properties that are distinct from each other. In our view, this methodological procedure fits the holistic character of Tynjälä's (2013) model quite well: As detailed below, for instance, the formative higher-order construct perceived organisational learning culture is comprised of several first-order constructs (facets) like supervisor support, coworker support, or learning conditions. All these 
facets form the perceived organisational learning culture (i.e., they are causal for the construct; Bollen and Ting 2000); however, they are not necessarily correlated with each other but might contribute to an organisation's learning culture independently. Thus, when one facet of perceived organisational learning culture changes, the second-order construct will change accordingly. Nevertheless, the aggregate of an overarching perceived organisational learning culture is "theoretically meaningful and parsimonious" (Law et al. 1998, p. 741). The same holds true for the secondorder constructs work-related attitudes and learning-related beliefs.

As detailed below, the two dependent factors participation in designated learning opportunities and engagement in workplace learning asked for frequency of prior participation and intensity in engagement, respectively. As supported by confirmatory tetrad analysis (Bollen and Ting 2000; modified for PLS by Gundergan et al. 2008), these factors were operationalised as reflective first-order constructs.

Compared to direct paths between the underlying first-order constructs, the relationship between these second-order constructs and any dependent variable most likely results in an attenuated amount of explained variance (e.g., Paunonen 1998). However, as discussed, the estimation of second-order constructs seems more appropriate for the relational level suggested in Tynjälä's (2013) model and the hypotheses tested here (even though this should result in lower $R^{2}$ estimates). Readers interested in direct bivariate correlations between any first-order facet and dependent variables will find this information readily in Table 1; readers interested in multiple regression coefficients between several first-order facets and dependent variables (i.e., without the attenuating second-order constructs) can do so easily by using the R function psych::setCor with Table 1 as input (Revelle 2019).

All constructs were measured using self-reporting scales with several items each (see below). Self-reports are an appropriate way to measure the construct of interest since within the 3-P model the determining factor for learning is how employees "see themselves as workers and learners as well as how they see their workplace as a working environment" (Tynjälä 2013, p. 15; see also Thomas theorem: Thomas and Thomas 1928).

Independent Variables The constructs used as independent variables in this study were defined and operationalised as follows (the number of items used for operationalisation; a measure of composite reliability, $C R$; and a sample item can be found in brackets after each construct). All items of the independent first-order constructs could be answered on a 5-point Likert scale ranging from $1=$ strongly disagree to $5=$ strongly agree.

- The second-order construct work-related attitudes is formed by how employees identify themselves with the work they do and how central this work is to their lives. It consists of the two dimensions job involvement (4 items, $C R=.86$; Maurer et al. 2003, e.g., "The most important things which happen to me involve my job.") and career planning (3 items, $C R=.79$; Gould 1979, e.g., "I know what I need to do to reach my career goals.").

- The second-order construct learning-related beliefs covers what Tynjälä (2013) calls "motivation" and "self-confidence". It is formed by the three dimensions attitudes towards learning ( 3 items, $C R=.88$; Maurer et al. 2003, e.g., "I feel favourably toward the idea of improving my career skills."), perceived benefits from learning (3 items, $C R=.86$; Maurer et al. 2003, e.g., "Participation in learning activities will help me get 


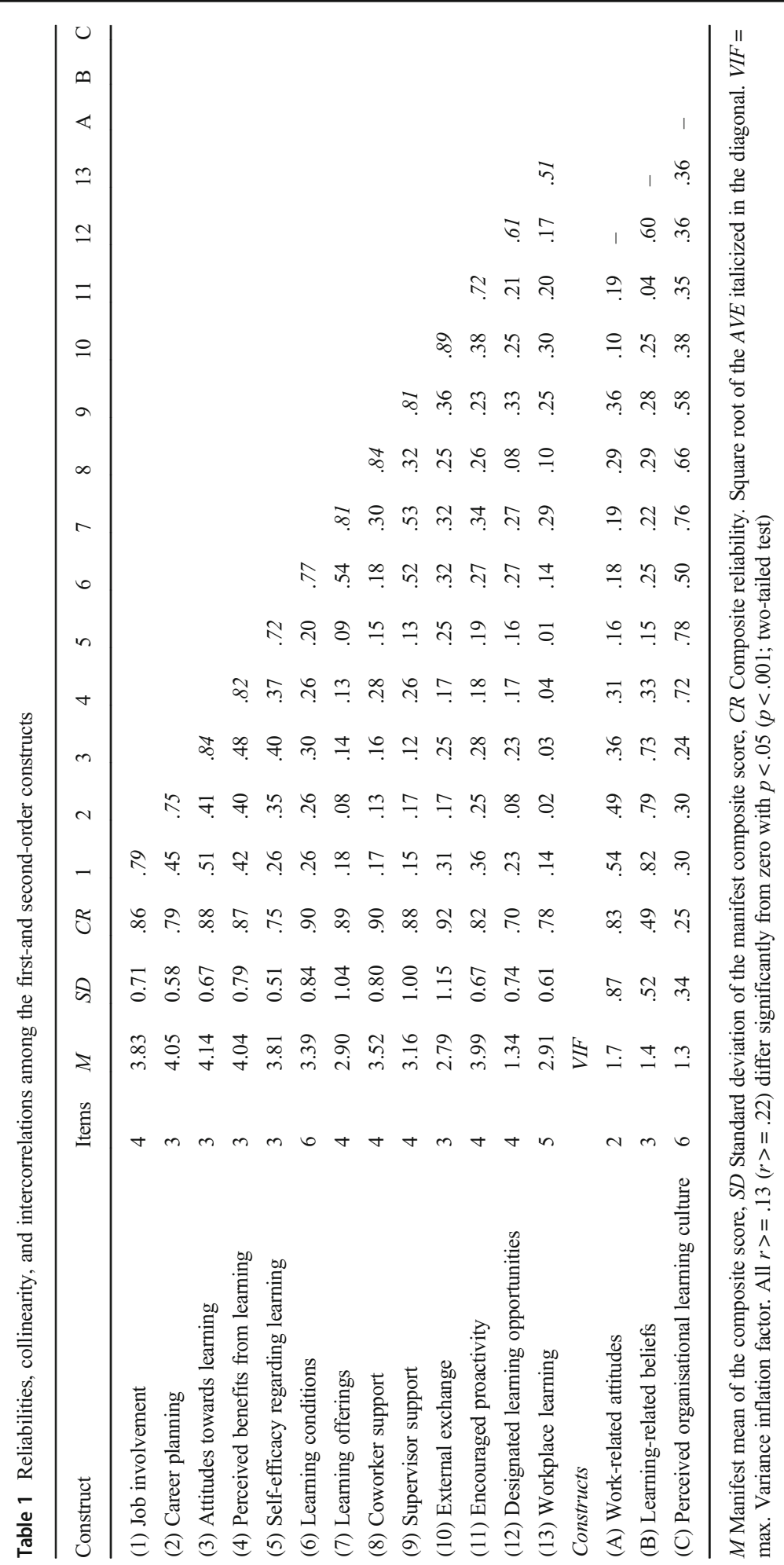


promotions into higher level jobs."), and self-efficacy in regard to learning (3 items, $C R=.75$; Maurer et al. 2003, e.g., "If I were to participate in a development activity, my success in that activity would be at least comparable to most other participants.").

- The second-order construct perceived organisational learning culture was operationalised using the recently developed learning culture inventory (Hilkenmeier et al. 2021, based on Schaper et al. 2005) consisting of one higherorder learning culture factor formed by six unidimensional subdimensions and covering a broad range of organisational variables conducive to learning described within the literature (e.g., Örtenblad 2004). Interpersonal support is covered by the two dimensions coworker support (4 items, $C R=.90$; e.g., "We as employees motivate each other to learn and try new things.") and supervisor support (4 items, $C R=.88$; e.g., "My supervisor encourages us to try new things, even though this experimentation might not lead to favourable outcomes."). Institutionalised support is covered by the two dimensions learning conditions within the organisation (6 items, $C R=.90$; e.g., "The development programs offered by the human resource department are tailored to our needs and requirements.") and learning offerings (4 items, $C R=.89$; e.g., "Our company provides internal networks for organised exchange of knowledge and experiences."). Empowerment is covered by the two dimensions external exchange ( 3 items, $C R=.92$; e.g., "I regularly exchange my knowledge externally, for instance with suppliers, clients or staff from other organisations or universities.") and encouraged proactivity (4 items, $C R=.82$; e.g., "My company expects me to broaden my professional knowledge and skills and to keep up to current developments on my own.”).

Dependent Variable: Participation in Designated Learning Opportunities This construct was operationalised by asking for the frequency of prior participation in different learning activities during the last 12 months (4 items, $C R=.70$; BMBF 2006, e.g., "During the last 12 months, I participated in the following number of courses/workshops.”). The answer scale ranged from $1=$ never to $5=$ more than six times.

Dependent Variable: Engagement in Workplace Learning This construct was operationalised by asking for intensity in engagement in different workplace learning activities during the given week (5 items, $C R=.77$; based on BMBF 2006, e.g., "experimenting at work", "observing and listening"). For each workplace learning activity, it was separately asked on a 5-point Likert scale ranging from $1=$ did not apply this week to $5=$ did strongly apply this week whether and to what extent the participant was engaged with it. Above the items it was explained that this kind of learning is not pre-planned but is connected to emerging work-related problems. The responses to these repeated questionnaires were averaged to increase reliability.

\section{Data Analysis}

A partial least square approach to structural equation modelling (PLS-SEM) using $R$ 's (R Core Team 2017) plspm 0.4.9 package (Sanchez et al. 2017) was adopted for data analysis. PLS-SEM allows testing of complex models (i.e., higher-order constructs, 
moderations, many relationships) with relatively small sample sizes even when data are abnormally distributed (e.g., Hair et al. 2017; Reinartz et al. 2009). Since our model exhibits all these characteristics, PLS-SEM was favoured over the more often used covariance-based SEM (CB-SEM) approach. In fact, it is quite likely that CB-SEM might not have been able to estimate the complex, proposed model because of sample size limitations. At the same time, simulation studies suggest that both CB-SEM and PLS-SEM often result in similar estimates (e.g., Reinartz et al. 2009). Recent guidelines for data analysis of PLS-SEM were followed (Hair et al. 2017).

Assessment of Measurement Model Data analysis was conducted in two separate steps. First, assessment focused on the measurement model, enabling us to evaluate the internal consistency (composite reliability, $C R$, which, in line with recent recommendations and the partial least square approach used here, was chosen over the more ubiquitously used Cronbach's $\alpha$ but can be interpreted in the same way, see e.g., Henseler et al. 2009) and validity evidence based on the internal structure of the model (Fornell-Larcker criterion, $F L$ for reflective fist-order constructs and variance inflation factor, VIF for second-order constructs). As Table 1 shows, all first-order constructs yielded satisfactory reliabilities ranging from .70 to .92 . To test whether the model's different constructs are truly distinct from each other and therefore whether they offer evidence for the internal structure of the model (AERA, APA, and NCME 2014), we employed the Fornell-Larcker criterion (Fornell and Larcker 1981) which compares two measures of variance: First, a variable's average variance extracted $(A V E)$, which represents the average amount of variance that a construct explains in its indicators; and second, the squared intercorrelations between the constructs in the contextual framework, representing the amount of variance a construct shares with each other construct. Distinctiveness is established when a construct is more closely related to its own indicators than to any other construct within the contextual framework. As can be seen in Table 1, the square root of each construct's $A V E$ (shown in the diagonal) is always higher than the highest correlation with any other construct, thus, indicating distinctiveness and therefore validity evidence based on the internal structure (Hilkenmeier et al. 2020).

The formative nature of our second-order constructs allows us to group variables, which do not need to be correlated with each other and which cover different aspects of a construct to form a common latent variable. Instead of calculating reliabilities it is therefore necessary to check for collinearity between the fist-order constructs that comprise the formative second-order construct. As can be seen from the lower part of Table 1, the resulting variance inflation factors $(V I F)$ are all smaller than 2. Collinearity within the formative second-order factors could therefore be ruled out as an issue. It follows that, based on these analyses, both the reflective first-order constructs as well as the formative second-order constructs can be used to estimate the assumed relationships in the structural model.

Model Specification and Estimation Since the evaluation of the measurement model produced satisfactory results, we continued with the second step of our data analysis focusing on the structural model and the hypothesised relationship. We specified our structural-equation model as a full model. That is, we included direct paths from all three second-order presage factors to both kinds of professional learning activities, as 
well as the interaction terms of perceived organisational learning culture with workrelated attitudes and learning-related beliefs on both kinds of professional learning activities. In addition, gender was used as a control variable on both the second-order constructs and the dependent first-order constructs. The estimation of the full model not only allows comparison of path coefficients via Henseler's (2007); also see Nitzl 2010) test, it also safeguards us from artificially overestimating hypothesised path coefficients by excluding non-hypothesised but relevant paths.

The variance-based PLS procedure is based on a series of OLS regressions. Thus, we again had to check for collinearity among the independent second-order factors of the presage component. The resulting variance inflation factors $(V I F)$ of work-related attitudes, learningrelated beliefs, perceived organisational learning culture, and the control variable gender range from 1.2 to 1.6. Therefore, we were able to proceed and estimate unbiased path coefficients. PLS-SEM estimation was done using the factor weighting scheme with standardised data. All significance tests were based on bootstrapping with 5000 resamples.

\section{Results}

Figure 3 shows the standardised path coefficients ( $\beta$, first figure on an arrow), the associated bootstrapped $t$-values (value in brackets after path coefficient), and the explained variance $\left(R^{2}\right)$ for each endogenous variable estimated by the PLS algorithm. For the sake of clarity, nonhypothesised paths that did not reach significance (two-tailed tests) were omitted (a full overview of the estimated path coefficients, including standard errors, $t$-values, and $p$ values, can be obtained from Appendix Table 2).

In line with hypotheses $H 1 a$ and $H 1 b$, work-related attitudes and perceived organisational learning culture indeed influence learning-related beliefs, explaining $38 \%$ of its variance, which indicates a strong effect (Cohen 1988).

More interesting in the present context are, however, the sizes and significances of the path coefficients between the presage and the process components. Taken together, all predictors in the model explain $18 \%$ of the variance of participation in designated learning opportunities and $14 \%$ of the variance of engagement in workplace learning (both medium effects). As predicted by hypothesis $H 2 a$, learning-related beliefs significantly predict participation in designated learning opportunities. Importantly, learning-related beliefs have no significant impact on workplace learning, giving a first indication of the advocated differential effects. Indeed, Henseler's test shows that the path coefficients from learning-related beliefs to participation in designated learning opportunities and engagement in workplace learning significantly differ, $t(456)=2.73$, $p<.01$. However, besides the significance of the standardised path coefficient, one should also interpret the (relative) importance of a given predictor - that is, its impact on an endogenous construct of interest (i.e., participation in designated learning opportunities and workplace learning, respectively; Hair et al. 2017). For this purpose, we calculated partial $f^{2}$. In other words, we calculated the full model with all predictors and then a reduced model without the respective predictor, in this case learning-related beliefs. The reduced model can still explain $13 \%$ in variance in workplace learning (compared to $14 \%$ with the full model, see Fig. 3), leaving not even a small partial effect for learning-related beliefs (increase of about 1 percentage point in explained 


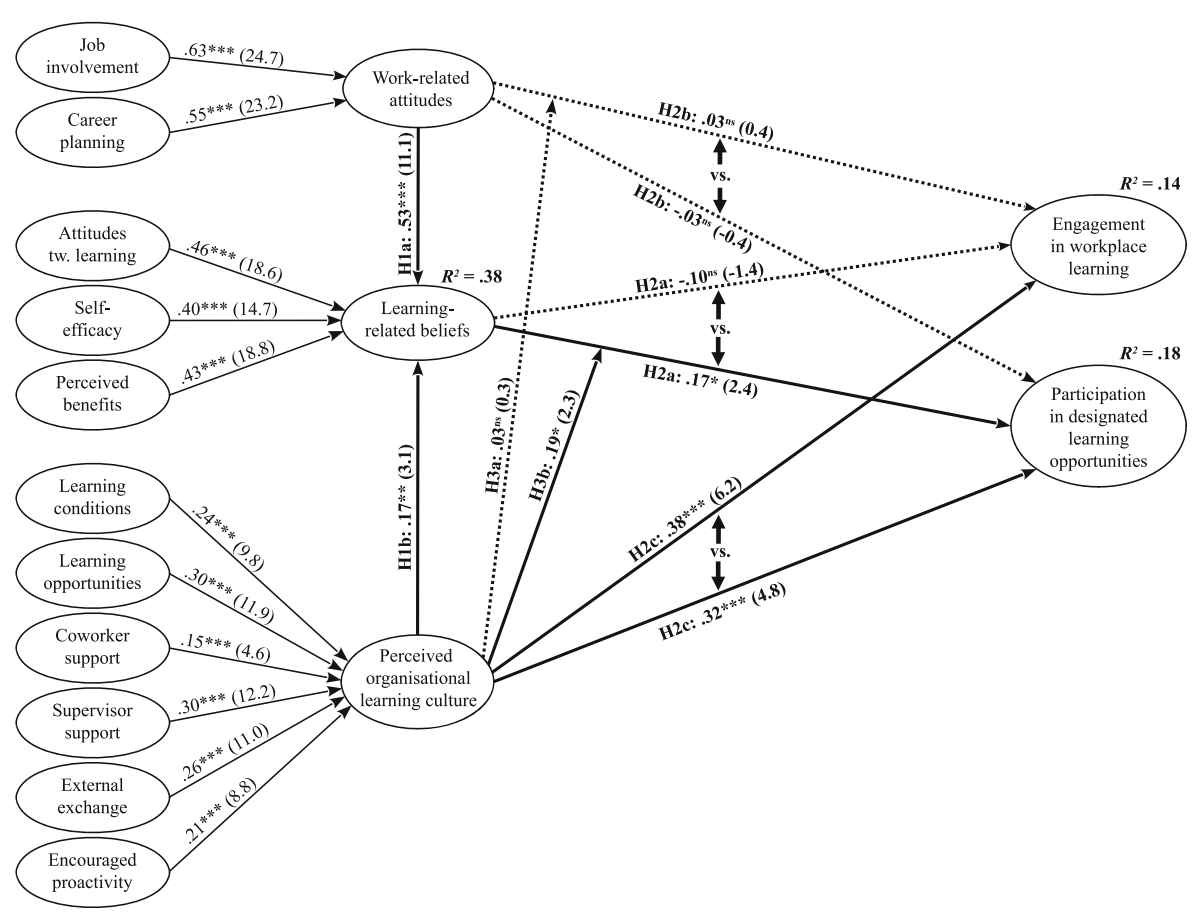

Fig. 3 PLS-based estimated structural equation model. Note. Solid path are significant, dotted paths are insignificant. Figures represent standardised path coefficients $(\beta)$. Figures in brackets represent corresponding bootstrapped $t$-values ( $t, \mathrm{df}=228,5000$ resamples). $R^{2}$ values depict explained variances for the corresponding latent constructs. Gender entered the structural model as a control variable but had no significant effect. ns $=$ not significant, $* p<.05, * * p<.01, * * * p<.001$ (two-tailed)

variance, $f^{2}$ partial $=.01$ ), which is in line with hypothesis $H 2 a$. Somewhat unexpectedly, the reduced model can still explain 15\% in variance in participation in designated learning opportunities, resulting in only a small partial effect for learning-related beliefs (increase of about 3 percentage points in explained variance, $f_{\text {partial }}=.02$ ). This indicates that the incremental effect of learning-related beliefs even on participation in designated learning opportunities is rather small.

As predicted, work-related attitudes did not affect participation in designated learning opportunities directly. However, neither did it influence workplace learning; neither directly nor indirectly. As expected in this situation, Henseler's test also produced a non-significant result, $t(456)=0.60, p=.27$. Consequently, the partial $f^{2}$ for work-related attitudes are near zero $\left(f^{2}\right.$ partial $=.01$ on participation in designated learning opportunities and $f^{2}$ partial $<.01$ on workplace learning, respectively). The reduced model without work-related attitudes can still explain $14 \%$ of the variance in workplace learning and $17 \%$ of the variance in participation in designated learning opportunities. Thus, hypothesis $H 2 b$ could not be supported by the empirical data.

As predicted by hypothesis $H 2 c$, there is a strong relationship between perceived organisational learning culture and workplace learning. However, the relationship between perceived organisational learning culture and participation in designated learning opportunities is also comparably large, Henseler's $t(456)=0.71, p=.24$. Likewise, the partial $f^{2}$ are similar in size as well, resulting in small-to-medium effects on both workplace learning and 
participation in designated learning opportunities ( $f_{\text {partial }}=.13$ and $f_{\text {partial }}=.12$, respectively). The reduced model without perceived organisational learning culture can only explain $3 \%$ of the variance in workplace learning and $8 \%$ of the variance in participation in designated learning opportunities. Thus, even though the advocated differential effects are not significant (rejecting hypothesis $\mathrm{H} 2 \mathrm{c}$ ), the empirical results show a strong influence of perceived learning culture on learning in general.

The interplay between organisational and individual factors was tested by using perceived organisational learning culture as a moderator variable between learningrelated beliefs and work-related attitudes, and participation in designated learning opportunities and workplace learning, respectively. As anticipated in hypothesis $H 3 b$, the moderator indeed affects the strength of the relationship between learning-related beliefs and participation in designated learning opportunities. However, the hypothesised moderator effect of work-related attitudes and workplace learning could not be found. This speaks against hypothesis $\mathrm{H3a}$.

\section{Discussion}

Research focusing on learning taking place at work, through work, and for work has become a topic of intense interest (Tynjälä 2013; see also recent edited volumes: Billett et al. 2014; Ellingson and Noe 2017; Messmann et al. 2018). Based on the 3-P model of learning, the goal of this study was to investigate the potentially differential influences of several antecedents of the presage component, namely work-related attitudes, learning-related beliefs, and perceived organisational learning culture on participation in designated learning opportunities and engagement in workplace learning. The rationale behind the hypothesised differential effects is that these two kind of learning activities are of a different nature: Whereas participation in designated learning opportunities - as the name suggests - takes place in organised designated learning settings, with clear learning objectives, and is intentional, engagement in workplace learning is in most cases unintentional from the learner's perspective, and the learned tacit skills arise as a by-product through participation in everyday work practices. Since workplace learning endeavours are therefore often not based on conscious decision processes, we suggested that learning-related beliefs such as attitudes towards learning, self-efficacy in regard to learning, or perceived benefits from learning should be much less important than they are for learning in designated training programs with special trainers and concerted schedules. For instance, "listening to a coworker about his attempt to solve a problem" should require less planning and less intention than enrolling in a training program. The empirical evidence of this study supports this line of argumentation, though with reservations.

Learning-related beliefs were indeed found to predict employees' participation in designated learning opportunities but not engagement in workplace learning. This speaks in favour of hypothesis $H 2 a$. Due to its often-unplanned nature, that is, usually not consciously directed towards the explicit aim of learning and professional development, engagement in workplace learning activities is not influenced by beliefs connected to learning. As discussed, this underlines the need for a comprehensive meta-theory of workplace learning (Cerasoli et al. 2017) that is different from the "meta" theory of planned behaviour (Ajzen 1991) for participation in designated 
learning opportunities, in which conscious beliefs toward learning play a central role (e.g., Hurtz and Williams 2009). However, the present study cannot offer any insights on which individual learner factors might potentially take on a comparable central theoretical role in a meta-theory of workplace learning. In contrast to our theoretical expectations, we did not find any evidence for a substantial effect of work-related attitudes on engagement in workplace learning, contradicting hypothesis $H 2 b$. Based on Rowold and Shilling (2006), for example, we expected that individuals who experience their jobs as central to their lives should more often engage in nonroutine situations that offer opportunities for workplace learning. However, the present study does not substantiate a direct link between work-related attitudes and actual engagement in more learning activities. One possible explanation might be that employees with more positive work-related attitudes indeed perceive more opportunities for learning, but therefore also perceive their organisational learning culture to be more conducive to learning. As can be seen from Table 1, work-related attitudes substantially correlate with the perceived organisational learning culture (and, fittingly, especially with the two empowerment-dimensions encouraged proactivity and external exchange), which might suggest such indirect effect where work-related attitudes affect how the organisational learning culture is perceived and this perception then explains engagement in workplace learning. In general, the perceived organisational learning culture exhibited considerable power to explain employees' engagement in workplace learning. As theoretically assumed, workplace learning is strongly affected by situational factors like coworker and supervisor support, or opportunities for boundary crossing, that all manifest in a pronounced organisational learning culture. At the same time, however, participation in designated learning opportunities is also strongly affected by the perceived organisational learning culture. That is why hypothesis $\mathrm{H} 2 \mathrm{c}$ has to be rejected since the expected differential effect between both kinds of learning activities could not be found. Instead, the learning context seems to be a more universal predictor for both kinds of professional learning activities. The perceived organisational learning culture is also positively associated with learning-related beliefs (hypothesis H1b). In other words, employees have more positive beliefs regarding learning and development if the culture of their organisational environment is generally conducive to learning. This is strongly in line with findings presented elsewhere in the literature (Maurer et al. 2003; Mathieu et al. 1992; LePine et al. 2004), resulting in an additional significant indirect effect on participation in designated learning opportunities via learning-related beliefs (Sobel test statistic $=3.1$, $p<.01$ ). In addition, learning-related beliefs were also found to be predicted by work-related attitudes as theoretically assumed (hypothesis H1a).

The importance of the work and learning context is further corroborated when turning to its moderating role. As outlined in the concept of co-participation (Billett 2001), employees should more often engage in learning if the workplace affords any opportunities for (workplace) learning or has an active human resource department that offers developmental programs. So over and above the significant direct (and indirect) influence of perceived organisational learning culture on both kind of learning activities, the work and learning context additionally should act like a gatekeeper that regulates how much of the employees' individual motivation or agentic efforts can actually turn into learning behaviour (see also Goller 2017). Within our study, empirical evidence was found only for this moderating role between the relationship of learning-related beliefs and participation in designated learning 
opportunities but not between work-related attitudes and workplace learning. This finding speaks in favour of hypothesis $H 3 b$ but not $H 3 a$.

Especially in the face of recent discussions about the importance of human agency and individuals' proactivity for workplace learning and professional development (e.g., Eteläpelto et al. 2013; Goller 2017; Goller and Paloniemi 2017), the relative relevance of organisational factors of the work and learning context reflected in the perceived organisational learning culture for both kind of learning activities is (at least in this dominance) somewhat unexpected and can be regarded as the main reason why we have to reject hypotheses $H 2 c$. The work and learning context was found to be the most dominant driver of learning activities in our study, giving only small room for other factors. However, we would argue it is actually good news for practitioners: Whereas individual learner variables like employees' job involvement or attitudes towards learning are mostly beyond managerial reach, organisations can institute policies, structures, and processes to create an environment that supports the acquisition and distribution of knowledge, provides opportunities to work collaboratively, engage in challenging work tasks, and reflects on work results, thereby fostering sustainable learning processes (e.g., Billett 2001; Fischer and O'Connor 2014). For instance, to foster encouraged proactivity and coworker support, Huys et al. (2005) suggest designing jobs that are composed of a coherent set of multiple executory tasks, integrating related preparatory and supportive tasks, and involving coordination of one's own responsibilities with those of others. Likewise, to boost learning opportunities, Smith (2001) suggests several implications like making knowledge sharing part of an employee's performance review and establishing (monetary) incentives for employees who spend a lot of time helping each other. Furthermore, shallow hierarchies and decentralised decision-making structures should help increase knowledge sharing within an organisation (see also the idea of the learning organisation: Gijbels and Spaenhoven 2012). Of course, these suggested implications require (at least in part) profound changes to the organisational structure and culture. Increasing the supervisor support is maybe a more reachable goal. Baron (2011) found that, especially for older and low-educated employees, supervisors can help overcome possible (mental) barriers and that their encouragement is an important precondition for future learning activities. Training supervisors to pay more attention to older, lower-educated employees' interests and needs should therefore be an inherent part of human resource management, reemphasising Eraut's (2004) statement "that of all the mechanisms used at organisational level to promote learning the most significant is likely to be the appointment and development of its managers" (p. 271).

Several limitations of this study should be highlighted. First, all findings are based on a relatively small sample of German employees. It remains unclear whether the overrepresentation of employees from the secondary sector as well as employees with higher formal education affected the results. In addition, a few participants exhibited a larger number of missing values and their data could therefore not be used for our analysis. It is unclear whether the removal of affected participants biased the results in any way. Second, participants were recruited using social networks based on self-selection. It cannot be ruled out that this led to an over-representation of participants interested in learning and development, thereby affecting the results of our study. Third, although this study adopted a multi-wave design it has-strictly speaking-still to be characterised as cross-sectional in nature. This is especially true for all findings concerning antecedents of participation in designated learning opportunities. Hence, any causal interpretations should be made with care. In general, both kind of learning activitites have been measured using different methods and at different time points. Although we argue 
that the respective measure is suited to the specific nature of the learning activity in question, it is unclear how these methodological differences affected the reported findings. Fourth, as outlined before, it is well known that employees often struggle to report about their workplace learning. To overcome this obstacle a diary-method approach was used that repeatedly asked participants about their learning regulation at work. At the same time, we still have to acknowledge that even this measurement mode is not able to capture learning activities that take place fully unconsciously. In other words, our study might underestimate the amount of employees' workplace learning. Regarding the measure of participation in designated learning opportunities, we did not differentiate whether participants engaged in their designated learning activities voluntarily or involuntarily, thus overestimating the "engagement" in these professional learning activities. How the estimated relationships between the drivers of professional learning in this study are affected by these issues, however, remains unclear. Moreover, we are unable to differentiate if an employee did not want to participate in (more) designated learning opportunities, or if there simply were not any (more) opportunities offered to the employee. Therefore, the results and thus the path coefficients reported here should probably be estimated too conservatively, which speaks to the robustness of the study and the results. Fifth, the diary-method approach might have caused a treatment effect. In other words, our participants might have changed their usual workplace learning behaviour due to the weekly survey. The presented questions might have stimulated them to engage in more workplace learning than they would usually. Sixth, only self-reporting measures were used in this study. It is unclear whether more objective measures - especially for the learning activities - would have resulted in other findings. Seventh, work-related attitudes, learningrelated beliefs, and perceived organisational learning culture were all modelled as formative second-order factors. Among other reasons this was done to specify a rather parsimonious model that can be estimated with a relatively small dataset. At the same time, we acknowledge that, due to the use of formative second-order factors within PLS-SEM with its primary objective to maximise the explanation of variance (Henseler et al. 2009), the empirical weighting of how strong the respective first-order constructs influence the second-order construct should be interpreted with care. However, as the main focus of this study is not on explaining how specific attitudes, beliefs, or cultural facets affect learning, but on how more general factors like work-related attitudes, learning-related beliefs, and perceived organisational learning culture explain learning, we think this caveat is acceptable (also see Sarstedt et al. 2016). Moreover, as discussed above, readers interested in multiple regression coefficients between several first-order facets and dependent variables (i.e., without the attenuating second-order constructs) can do so easily by using the R function psych::setCor with Table 1 as input.

\section{Conclusion}

The present results indicate that-unlike participation in designated learning opportunities - engagement in workplace learning is not influenced by conscious beliefs connected to learning. This further underlines the need for a comprehensive metatheory of workplace learning that is different from the "meta" theory of planned behaviour in which conscious beliefs toward learning play a central role. However, we could not identify which other individual learner factors in lieu of learning-related beliefs could predict workplace learning. Instead, the current 
study shows unexpectedly strong direct, indirect, and moderating influences of organisational factors of the learning context on both kind of professional learning activities. Hence, future researchers as well as practitioners should put greater emphasis on organisational factors when investigating and designing learning opportunities.

\section{Appendix}

Table 2 Estimated paths based on PLS-SEM

\begin{tabular}{|c|c|c|c|c|}
\hline Paths & $\beta$ & $S E$ & $t$ & $p$ \\
\hline \multicolumn{5}{|l|}{ Control variables } \\
\hline Gender $\rightarrow$ Workplace learning & 0.01 & 0.06 & 0.24 & .81 \\
\hline Gender $\rightarrow$ Designated learning opportunities & 0.06 & 0.06 & 1.01 & .31 \\
\hline Gender $\rightarrow$ Learning-related beliefs & 0.02 & 0.05 & 0.3 & .74 \\
\hline Gender $\rightarrow$ Work-related attitudes & 0.08 & 0.07 & 1.2 & .22 \\
\hline Gender $\rightarrow$ Perceived organisational learning culture & -0.03 & 0.06 & -0.53 & .60 \\
\hline \multicolumn{5}{|l|}{ Formative second-order measurement model } \\
\hline Career planning $\rightarrow$ Work-related attitudes & 0.55 & 0.02 & 23.23 & $<.001$ \\
\hline Job involvement $\rightarrow$ Work-related attitudes & 0.63 & 0.03 & 24.65 & $<.001$ \\
\hline Attitudes towards learning $\rightarrow$ Learning-related beliefs & 0.46 & 0.02 & 18.65 & $<.001$ \\
\hline Self-efficacy regarding learning $\rightarrow$ Learning-related beliefs & 0.40 & 0.03 & 14.65 & $<.001$ \\
\hline Perceived benefits from learning $\rightarrow$ Learning-related beliefs & 0.43 & 0.02 & 18.78 & $<.001$ \\
\hline Learning conditions $\rightarrow$ Perceived organisational learning culture & 0.24 & 0.02 & 9.77 & $<.001$ \\
\hline Learning offerings $\rightarrow$ Perceived organisational learning culture & 0.30 & 0.02 & 11.90 & $<.001$ \\
\hline Coworker support $\rightarrow$ Perceived organisational learning culture & 0.15 & 0.03 & 4.59 & $<.001$ \\
\hline Supervisor support $\rightarrow$ Perceived organisational learning culture & 0.30 & 0.02 & 12.22 & $<.001$ \\
\hline External exchange $\rightarrow$ Perceived organisational learning culture & 0.26 & 0.02 & 11.08 & $<.001$ \\
\hline Encouraged proactivity $\rightarrow$ Perceived organisational learning culture & 0.21 & 0.02 & 8.75 & $<.001$ \\
\hline \multicolumn{5}{|l|}{ Direct relationships } \\
\hline Work-related attitudes $\rightarrow$ Learning-related beliefs & 0.53 & 0.04 & 11.09 & $<.001$ \\
\hline Perceived organisational learning culture $\rightarrow$ Learning-related beliefs & 0.17 & 0.05 & 3.13 & .002 \\
\hline Learning-related beliefs $\rightarrow$ Workplace learning & -0.10 & 0.07 & -1.43 & .152 \\
\hline Learning-related beliefs $\rightarrow$ Designated learning opp. & 0.17 & 0.07 & 2.43 & .016 \\
\hline Work-related attitudes $\rightarrow$ Workplace learning & 0.03 & 0.08 & 0.41 & .684 \\
\hline Work-related attitudes $\rightarrow$ Designated learning opp. & -0.03 & 0.08 & -0.44 & .658 \\
\hline Perceived organisational learning culture $\rightarrow$ Workplace learning & 0.38 & 0.06 & 6.24 & $<.001$ \\
\hline Perceived organisational learning culture $\rightarrow$ Designated learning opp. & 0.32 & 0.07 & 4.82 & $<.001$ \\
\hline \multicolumn{5}{|l|}{ Moderators } \\
\hline Perceived organisational learning culture $*$ Work-related attitudes $\rightarrow$ Workplace learning & 0.03 & 0.08 & 0.32 & .748 \\
\hline $\begin{array}{l}\text { Perceived organisational learning culture * Learning-related beliefs } \rightarrow \text { Designated learning } \\
\text { opportunities }\end{array}$ & 0.19 & 0.08 & 2.31 & .022 \\
\hline $\begin{array}{l}\text { Perceived organisational learning culture * Work-related attitudes } \rightarrow \text { Designated learning } \\
\text { opportunities }\end{array}$ & -0.14 & 0.09 & -1.62 & .106 \\
\hline Perceived organisational learning culture $*$ Learning-related beliefs $\rightarrow$ Workplace learning & 0.07 & 0.08 & -0.88 & .380 \\
\hline
\end{tabular}

$\beta$ Standardised path coefficient, $S E$ Standard error of $\beta, t=$ Bootstrapped t-value $(N=229,5000$ resamples). $p=$ Bootstrapped $\mathrm{p}$ value of $\mathrm{t}$-test (two-tailed) 
Acknowledgements We would like to express our gratitude to Margret Fromme-Ruthmann as well as Janine Stein for the collection of parts of the data of this study within the context of larger research projects.

Funding Open Access funding enabled and organized by Projekt DEAL.

Open Access This article is licensed under a Creative Commons Attribution 4.0 International License, which permits use, sharing, adaptation, distribution and reproduction in any medium or format, as long as you give appropriate credit to the original author(s) and the source, provide a link to the Creative Commons licence, and indicate if changes were made. The images or other third party material in this article are included in the article's Creative Commons licence, unless indicated otherwise in a credit line to the material. If material is not included in the article's Creative Commons licence and your intended use is not permitted by statutory regulation or exceeds the permitted use, you will need to obtain permission directly from the copyright holder. To view a copy of this licence, visit http://creativecommons.org/licenses/by/4.0/.

\section{References}

Ajzen, I. (1991). The theory of planned behavior. Organizational Behavior and Human Decision Processes, 50, 179-211. https://doi.org/10.1016/0749-5978(91)90020-T.

American Educational Research Association (AERA), American Psychological Association (APA), \& National Council on Measurement in Education (NCME). (2014). Standards for educational and psychological testing. Washington: American Educational Research Association.

Baron, S. (2011). Workplace learning: subjective motives and supervisor support matter. Wiesbaden: VS Verlag. https://doi.org/10.1007/978-3-531-92870-8_1.

Berg, S. A., \& Chyung, S. Y. (2008). Factors that influence informal learning in the workplace. Journal of Workplace Learning, 20(4), 229-244. https://doi.org/10.1108/13665620810871097.

Biggs, J. (1999). Teaching for quality learning at university. What the student does. Buckhingham: Society for Research into Higher Education \& Open University Press.

Billett, S. (2001). Learning through work: workplace affordances and individual engagement. Journal of Workplace Learning, 13(5), 209-214. https://doi.org/10.1108/EUM0000000005548.

Billett, S. (2004). Workplace participatory practices: conceptualising workplaces as learning environments. Journal of Workplace Learning, 16(6), 312-324.

Billett, S. (2014). Mimetic learning at work: learning in the circumstances of practice. Dordrecht: Springer.

Billett, S., Harteis, C., \& Gruber, H. (Eds.). (2014). International handbook of research in professional and practice-based learning. Dordrecht: Springer.

Blume, B. D., Ford, J. K., Baldwin, T. T., \& Huang, J. L. (2010). Transfer of training: a meta-analytic review. Journal of Management, 36, 1065-1105. https://doi.org/10.1177/0149206309352880.

BMBF (2006). Berichtssystem Weiterbildung IX. Integrierter Gesamtbericht zur Weiterbildungssituation in Deutschland [Report system further education IX. Integrated report concerning the situation of further education in Germany]. Bonn: Bundesministerium für Bildung und Forschung.

Bollen, K. A., \& Ting, K. (2000). A tetrad test for causal indicators. Psychological Methods, 5, 3-22.

Butler, J., \& Brooker, R. (1998). The learning context within technical and further education colleges as perceived by apprentices and their workplace supervisors. Journal of Vocational Education \& Training, 50(1), 79-96.

Cerasoli, C. P., Alliger, G. M., Donsbach, J. S., Mathieu, J. E., Tannenbaum, S. I., \& Orvis, K. A. (2017). Antecedents and outcomes of informal learning behaviors: a meta-analysis. Journal of Business and Psychology, 33, 203-230.

Clardy, A. (2000). Learning on their own: vocationally oriented self-directed learning projects. Human Resource Development Quarterly, 11, 105-125.

Cohen, J. (1988). Statistical power analysis for the behavioral sciences (2nd ed.). Hillsdale: Lawrence Erlbaum Associates.

Decker, S., \& Martino, S. (2013). Unintended effects of training on clinicians' interest, confidence, and commitment in using motivational interviewing. Drug and Alcohol Dependence, 132(3), 681-687.

Diamantopoulos, A., Riefler, P., \& Roth, K. P. (2008). Advancing formative measurement models. Journal of Business Research, 61, 1203-1218. 
Doornbos, A. J., Bolhuis, S., \& Denessen, E. (2004). Exploring the relation between work domains and workrelated learning: the case of the Dutch police force. International Journal of Training and Development, 8(3), 174-190. https://doi.org/10.1111/j.1360-3736.2004.00207.x.

Ellingson, J. E., \& Noe, R. A. (Eds.). (2017). Autonomous learning in the workplace. New York: Routledge.

Eraut, M. (2000). Non-formal learning and tacit knowledge in professional work. British Journal of Educational Psychology, 70(1), 113-136. https://doi.org/10.1348/000709900158001.

Eraut, M. (2004). Informal learning in the workplace. Studies in Continuing Education, 26, 247-273. https:// doi.org/10.1080/158037042000225245.

Eteläpelto, A., Vähäsantanen, K., Hökkä, P., \& Paloniemi, S. (2013). What is agency? Conceptualizing professional agency at work. Educational Research Review, 10, 45-65. https://doi.org/10.1016/j.edurev. 2013.05.001.

Facteau, J. D., Dobbins, G. H., Russell, J. E. A., Ladd, R. T., \& Kudisch, J. D. (1995). The influence of general perceptions of the training environment on pretraining motivation and perceived training transfer. Journal of Management, 21, 1-25.

Fischer, C., \& O’Connor, B. N. (2014). Informal learning in workplaces: understanding learning culture as a challenge for organizational and individual development. In C. Harteis, A. Rausch, \& J. Seifried (Eds.), Discourses on professional learning: on the boundary between learning and working (pp. 11-24). Dordrecht: Springer.

Fornell, C., \& Larcker, D. F. (1981). Evaluating structural equation models with unobservable variables and measurement error. Journal of Marketing Research, 18, 39-50.

Fuller, A., \& Unwin, L. (2004). Expansive learning environments: integrating organizational and personal development. In H. Rainbird, A. Fuller, \& A. Munro (Eds.), Workplace learning in context (pp. 126-144). London: Routledge.

Gegenfurtner, A., Veermans, K., Festner, D., \& Gruber, H. (2009). Motivation to transfer training: an integrative literature review. Human Resource Development Review, 8, 403-423. https://doi.org/10. $1177 / 1534484309335970$.

German Federal Statistical Office (2018). Bevölkerung und Erwerbstätigkeit. Mikrozensus. Fachserie 1, Reihe 4.1 [Population and employment. Microcensus]. Wiesbaden: Statistisches Bundesamt.

German Federal Statistical Office (2019). Jahr 2018: Anstieg der Erwerbstätigkeit setzt sich fort. [2018: Employment continues to rise.]. Wiesbaden: Statistisches Bundesamt Retrieved from https://www. destatis.de/DE/Presse/Pressemitteilungen/2019/01/PD19_001_13321.html.

Gijbels, D., Raemdonck, I., Vervecken, D., \& Van Herck, J. (2012). Understanding work-related learning: the case of ICT workers. Journal of Workplace Learning, 24, 416-429.

Gijbels, D., \& Spaenhoven, R. (2012). On organistational learning: C. Argyris. In F. Dochy, D. Gijbels, M. Segers, \& P. Van den Bossche (Eds.), Theories of learning for the workplace: building blocks for training and professional development programmes (pp. 115-124). London: Routledge.

Goller, M. (2017). Human agency at work: an active approach towards expertise development. Wiesbaden: Springer VS.

Goller, M., \& Billett, S. (2014). Agentic behaviour at work: crafting learning experiences. In C. Harteis, A. Rausch, \& J. Seifried (Eds.), Discourses on professional learning: on the boundary between learning and working (pp. 25-44). Dordrecht: Springer.

Goller, M., \& Paloniemi, S. (Eds.). (2017). Agency at work: an agentic perspective on professional learning and development. Cham: Springer.

Gould, S. (1979). Characteristics of career planners in upwardly mobile occupations. Academy of Management Journal, 22, 539-550. https://doi.org/10.2307/255743.

Govaerts, N., Kyndt, E., Vreye, S., \& Dochy, F. (2017). A supervisors' perspective on their role in transfer of training. Human Resource Development Quarterly, 28(4), 515-552. https://doi.org/10.1002/hrdq.21286.

Gruber, H., \& Harteis, C. (2018). Individual and social influences on professional learning: supporting the acquisition and maintenance of expertise. Cham: Springer.

Gundergan, S. P., Ringle, C. M., Wende, S., \& Will, A. (2008). Confirmatory tetrad analysis in PLS path modeling. Journal of Business Research, 61, 1238-1249.

Hair, J. F., Hult, G. T. M., Ringle, C. M., \& Sarstedt, M. (2017). A primer on partial least squares structural equation modeling (PLS-SEM) (2nd ed.). Thousand Oaks: Sage.

He, T., \& Zhu, C. (2017). Digital informal learning among Chinese university students: the effects of digital competence and personal factors. International Journal of Educational Technology in Higher Education, 14(1), 14-44.

Henseler, J. (2007). A new and simple approach to multi-group analysis in partial least squares path modeling. In H. Martens \& T. Næs (Eds.), Causalities explored by indirect observation: proceedings of the 5th international symposium on PLS and related methods (PLS'07) (pp. 104-107). Oslo. 
Henseler, J., Ringle, C., \& Sinkovics, R. (2009). The use of partial least squares path modeling in international marketing. Advances in International Marketing, 20, 277-319.

Hilkenmeier, F., Bohndick, C., Bohndick, T., \& Hilkenmeier, J. (2020). Assessing distinctiveness in multidimensional instruments without access to raw data-a manifest Fornell-Larcker criterion. Frontiers in Psychology, 11, 223.

Hilkenmeier, F., Schaper, N., \& Goller, M. (2021). Development and validation of the learning culture inventory [Unpublished manuscript]. Psychology School, Hochschule Fresenius.

Hurtz, G. M., \& Williams, K. J. (2009). Attitudinal and motivational antecedents of participation in voluntary employee development activities. Journal of Applied Psychology, 94, 635-653. https://doi.org/10.1037/ a0014580.

Huys, R., De Rick, K., \& Vandenbrande, T. (2005). Enhancing learning opportunities at work. Leuven: Hoger instituut voor de arbeid, Katholieke Universiteit Leuven. Retrieved from http:/hdl.voced.edu.au/ 10707/88355. Accessed 4 April 2021.

ILO. (1974). Paid educational leave convention. Geneva: ILO. Retrieved from: http://www.ilo.org/dyn/ normlex/en/f?p=NORMLEXPUB:12100:0::NO::P12100_INSTRUMENT_ID:312285.

Ito, J. K., \& Brotheridge, C. M. (2005). Does supporting employees' career adaptability lead to commitment, turnover or both? Human Resource Management, 44, 5-19. https://doi.org/10.1002/hrm.20037.

Janz, B. D., \& Prasarnphanich, P. (2003). Understanding the antecedents of effective knowledge management: the importance of a knowledge-centered culture. Decision Sciences, 34, 351-384.

Kyndt, E., \& Baert, H. (2013). Antecedents of employees' involvement in work-related learning: a systematic review. Review of Educational Research, 83, 273-313. https://doi.org/10.3102/0034654313478021.

Kyndt, E., Dochy, F., \& Nijs, H. (2009). Learning conditions for non-formal and informal workplace learning. Journal of Workplace Learning, 21(5), 369-383. https://doi.org/10.1108/13665620910966785.

Kyndt, E., Govaerts, N., Smet, K., \& Dochy, F. (2018). Antecedents of informal workplace learning: a theoretical study. In G. Messmann, M. Segers, \& F. J. R. C. Dochy (Eds.), Informal learning at work: triggers, antecedents, and consequences (pp. 12-39). Abingdon: Routledge.

Law, K. S., Wong, C., \& Mobley, W. H. (1998). Toward a taxonomy of multidimensional constructs. Academy of Management Review, 23, 741-755.

LePine, J. A., LePine, M. A., \& Jackson, C. L. (2004). Challenge and hin- drance stress: relationships with exhaustion, motivation to learn, and learning performance. Journal of Applied Psychology, 89, 883-891.

Li, F., \& Liu, P. (2014). Review of organizational learning culture from the perspective of self-dependent innovation. Journal of Chinese Economics, 2, 53-61.

Lohmann, M. (2006). Factors influencing teachers' engagement in informal learning activities. Journal of Workplace Learning, 18(3), 141-156.

Marsick, V. J., \& Watkins, K. (2015). Informal and incidental learning in the workplace. Abingdon: Routledge.

Mathieu, J. E., Tannenbaum, S. I., \& Salas, E. (1992). The influences of individual and situational characteristics on measures of training effectiveness. Academy of Management Journal, 35, 828-847.

Maurer, T., \& Tarulli, B. (1994). Perceived environment, perceived outcome, and person variables in relationship to voluntary development activity by employees. Journal of Applied Psychology, 79, 3-14. https://doi.org/10.1037/0021-9010.79.1.3.

Maurer, T. J., Weiss, E. M., \& Barbeite, F. G. (2003). A model of involvement in work-related learning and development activity: the effects of individual, situational, motivational and age variables. Journal of Applied Psychology, 88, 707-724. https://doi.org/10.1037/0021-9010.88.4.707.

Messmann, G., Segers, M., \& Dochy, F. J. R. C. (Eds.). (2018). Informal learning at work: triggers, antecedents, and consequences. Abingdon: Routledge.

Nieuwenhuis, L. F. M., \& van Woerkom, M. (2007). Goal rationalities as a framework for evaluating the learning potential of the workplace. Human Resource Development Review, 6(1), 64-83. https://doi.org/ $10.1177 / 1534484306296432$.

Nitzl, C. (2010). Eine anwenderorientierte Einführung in partial Least Square (PLS)-Methode (a useroriented introduction to partial least squares (PLS) method). Hamburg: University of Hamburg. https://doi.org/10.2139/ssrn.2097324.

Noe, R. A. (1986). Trainees' attributes and attitudes: Neglected influences on training effectiveness. The Academy of Management Review, 11(4), 736-749. https://doi.org/10.2307/258393.

Noe, R. A., \& Schmitt, N. (1986). The influence of trainee attitudes on training effectiveness: test of a model. Personnel Psychology, 39, 497-523.

Örtenblad, A. (2004). The learning organization: towards an integrated model. The Learning Organization, 11, 129-144. https://doi.org/10.1108/09696470410521592. 
Park, J., Abrahams, I., \& Song, J. (2016). Unintended knowledge learnt in primary science practical lessons. International Journal of Science Education, 38(16), 2528-2549.

Paunonen, S. V. (1998). Hierarchical organization of personality and prediction of behavior. Journal of Personality and Social Psychology, 74(2), 538-556. https://doi.org/10.1037/0022-3514.74.2.538.

Pierce, H. R., \& Maurer, T. J. (2009). Linking employee development activity, social exchange and organizational citizenship behavior. International Journal of Training and Development, 13, 139-147. https://doi.org/10.1111/j.1468-2419.2009.00323.x.

R Core Team. (2017). R: a language and environment for statistical computing. Vienna: R Foundation for Statistical Computing Retrieved from https://www.R-project.org/.

Rausch, A. (2013). Task characteristics and learning potentials - Empirical results of three diary studies on workplace learning. Vocations and Learning, 6(1), 55-79. https://doi.org/10.1007/s12186-012-9086-9.

Rausch, A. (2014). Using diaries in research on work and learning. In C. Harteis, A. Rausch, \& J. Seifried (Eds.), Discourses on professional learning: on the boundary between learning and working (pp. 341366). Dordrecht: Springer.

Reinartz, W., Haenlein, M., \& Henseler, J. (2009). An empirical comparison of the efficacy of covariancebased and variance-based SEM. International Journal of Research in Marketing, 26(4), 332-344. https:// doi.org/10.1016/j.ijresmar.2009.08.001.

Revelle, W. (2019). psych: procedures for psychological, psychometric, and personality research. Retrieved April 4, 2021 from https://CRAN.R-project.org/package=psych.

Richter, D., Kunter, M., Klusmann, U., Lüdtke, O., \& Baumert, J. (2011). Professional development across the teaching career: teachers' uptake of formal and informal learning opportunities. Teaching and Teacher Education, 27, 116-126. https://doi.org/10.1016/j.tate.2010.07.008.

Rowold, J., \& Shilling, J. (2006). Career-related continuous learning: longitudinal predictive power of employees' job and career attitudes. Career Development International, 11, 489-503. https://doi.org/ $10.1108 / 13620430610692917$.

Sanchez, G., Trinchera, L., \& Russolillo, G. (2017). plspm: Tools for partial least squares path modeling (PLS-PM). Retrieved April 4, 2021 from https://cran.r-project.org/src/contrib/Archive/plspm/.

Sarstedt, M., Hair, J. F., Ringle, C. M., Thiele, K. O., \& Gudergan, S. P. (2016). Estimation issues with PLS and CBSEM: where the bias lies. Journal of Business Research, 69, 3998-4010.

Schaper, N., Friebe, J., \& Sonntag, K. (2005). Erfassung und Bewertung Unternehmensbezogener Lernkulturen [Measurement and appraisal of organizational learning cultures]. In J. Erpenbeck (Ed.), Kompetenzmessung im Unternehmen. Lernkultur- und Kompetenzanalysen im betrieblichen Umfeld (pp. 19-340). Münster: Waxmann.

Schulz, M., \& Stamov-Roßnagel, C. S. (2010). Informal workplace learning: an exploration of age differences in learning competence. Learning and Instruction, 20, 383-399. https://doi.org/10.1016/j.learninstruc. 2009.03.003.

Simons, P. R. J., \& Ruijters, M. C. P. (2001). Work-related learning: elaborate, expand and externalize. In W. J. Nijhof \& L. F. M. Nieuwenhuis (Eds.), The dynamics of VET and HRD systems (pp. 101-114). Enschede: Twente University Press.

Smith, E. A. (2001). The role of tacit and explicit knowledge in the workplace. Journal of Knowledge Management, 5(4), 311-321. https://doi.org/10.1108/13673270110411733.

Thomas, W. I., \& Thomas, D. S. (1928). The child in America: behavior problems and programs. New York: Alfred A. Knopf.

Tynjälä, P. (2008). Perspectives into learning at the workplace. Educational Research Review, 3, $130-154$. https://doi.org/10.1016/j.edurev.2007.12.001.

Tynjälä, P. (2013). Toward a 3-P model of workplace learning: a literature review. Vocations and Learning, 6 , 11-36. https://doi.org/10.1007/s12186-012-9091-z.

van der Heijden, B., Boon, J., van der Klink, M., \& Meijs, E. (2009). Employability enhancement through formal and informal learning: an empirical study among Dutch non-academic university staff members. International Journal of Training and Development, 13, 19-37.

Vaughan, K. (2008). Workplace learning: a literature review. Wellington: NZCER Press.

Wertsch, J. W. (1998). Mind as action. New York: Oxford University Press.

Publisher's Note Springer Nature remains neutral with regard to jurisdictional claims in published maps and institutional affiliations.

Frederic Hilkenmeier studied psychology at the University of Hamburg and obtained his Ph.D. from the University of Paderborn in 2012. He is currently working as a lecturer and researcher in the psychology 
department at Fresenius University of Applied Sciences on projects dealing with the impact of organizational context factors as well as individual motivational factors on learning and performance.

Michael Goller is a research associate at the Institute of Educational Science at Paderborn University and a visiting professor of Empirical Research Methods in Educational Science at the University of Jena. He studied business and human resource education at the University of Jena and University of Kent in Canterbury. For his $\mathrm{Ph} . \mathrm{D}$., he went to Paderborn and focused on the relationship of human agency and expertise development in the domain of geriatric care nursing. His current research interests comprise the role of human agency in professional learning and development, expertise development and workplace learning in general, as well as the integration of formal and informal learning environments.

Niclas Schaper studied psychology at the University of Göttingen and obtained his Ph.D from the University of Kassel in 1994. Since 2004, he is a full-professor of work and organizational psychology at the University of Paderborn. His research interests are in applied, personell and educational psychology.

\section{Affiliations}

\section{Frederic Hilkenmeier $^{1} \cdot$ Michael Goller $^{2} \cdot$ Niclas Schaper $^{3}$}

1 Psychology School, Hochschule Fresenius, Alte Rabenstraße 1, D-20148 Hamburg, Germany

2 Institute of Educational Science, University of Paderborn, Technologiepark 21, 33100 Paderborn, Germany

3 Work-and Organizational Psychology, University of Paderborn, Warburger Str. 100, D-33100 Paderborn, Germany 